
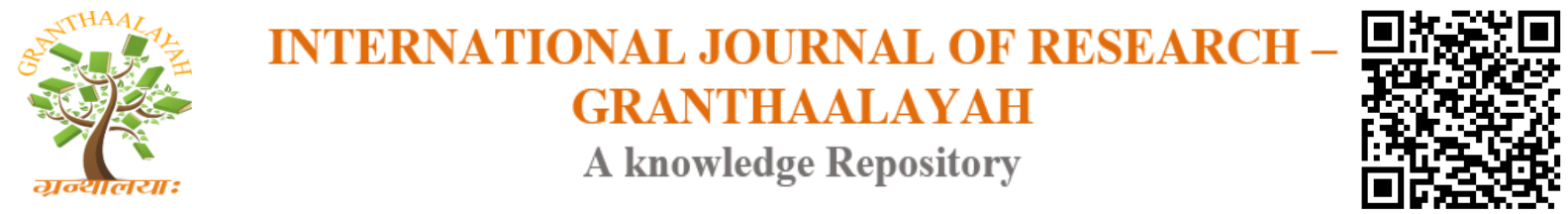

Science

\title{
REDUCTION OF ACTIVE POWER LOSS BY IMPROVED FROG LEAPING ALGORITHM
}

\author{
Dr.K.Lenin ${ }^{* 1}$ \\ ${ }^{* 1}$ Department of EEE Prasad V.Potluri Siddhartha Institute of Technology, Kanuru, Vijayawada, \\ Andhra Pradesh, India
}

\begin{abstract}
This paper presents Improved Frog Leaping (IFL) algorithm for solving optimal reactive power problem. Comprehensive exploration capability of Particle Swarm Optimization (PSO) and good local search ability of Frog Leaping Algorithm (FLA) has been hybridized to solve the reactive power problem and it overcomes the shortcomings of premature convergence. In order to evaluate the validity of the proposed Improved Frog Leaping (IFL) algorithm, it has been tested in Standard IEEE 57,118 bus systems and compared to other standard algorithms. Simulation results show that proposed Improved Frog Leaping (IFL) algorithm has reduced the real power loss considerably and voltage profiles are within the limits.
\end{abstract}

Keywords: Optimal Reactive Power; Transmission Loss; Frog Leaping Algorithm; Particle Swarm Optimization.

Cite This Article: Dr.K.Lenin. (2017). "REDUCTION OF ACTIVE POWER LOSS BY IMPROVED FROG LEAPING ALGORITHM." International Journal of Research - Granthaalayah, 5(9), 44-51. https://doi.org/10.29121/granthaalayah.v5.i9.2017.2197.

\section{Introduction}

Different numerical methods have been implemented to solve this optimal reactive power dispatch problem. These consist of the gradient method [1, 2], Newton method [3] and linear programming [4-7].The gradient and Newton methods suffer from the difficulty in handling inequality constraints. To apply linear programming, the input- output function is to be expressed as a set of linear functions which may lead to loss of accuracy. In recent times Global Optimization techniques such as genetic algorithms have been proposed to solve the reactive power flow problem [8.9]. In recent years, the problem of voltage stability and voltage collapse has become a major concern in power system planning and operation. To enhance the voltage stability, voltage magnitudes alone will not be a reliable indicator of how far an operating point is from the collapse point [10]. Particle Swarm Optimization (PSO) algorithm [11, 12] was originally an evolutionary computation technique, from observation and study of the predatory behaviour of birds. Frog Leaping Algorithm (FLA) [13] is swarm intelligence based subheuristic computation optimization algorithm used to solve discrete combinatorial optimization 
problem. The two algorithms are simple in concept, have less parameter, fast calculation speed, global search capability, and are easy to implement. This paper presents Improved Frog Leaping (IFL) algorithm for solving optimal reactive power problem. Global exploration capability of Particle Swarm Optimization (PSO) and good local search capability of Frog Leaping Algorithm (FLA) has been hybridized to solve the reactive power problem and it overcomes the shortcomings of premature convergence. In order to evaluate the validity of the proposed Improved Frog Leaping (IFL) algorithm, it has been tested in Standard IEEE 57,118 bus systems and compared to other standard algorithms. Simulation results show that proposed Improved Frog Leaping (IFL) algorithm has reduced the real power loss considerably and voltage profiles are within the limits.

\section{Objective Function}

Active power loss

Main aim of the reactive power dispatch problem is to reduce the active power loss in the transmission network, which can be described as:

$F=P L=\sum_{k \in N b r} g_{k}\left(V_{i}^{2}+V_{j}^{2}-2 V_{i} V_{j} \cos \theta_{i j}\right)$

Where $g_{\mathrm{k}}$ : is the conductance of branch between nodes $\mathrm{i}$ and $\mathrm{j}$, Nbr: is the total number of transmission lines in power systems.

\section{Voltage profile improvement}

For minimization of the voltage deviation in PQ buses, the objective function turns into:

$F=P L+\omega_{v} \times V D$

Where $\omega_{\mathrm{v}}$ : is a weighting factor of voltage deviation.

$\mathrm{VD}$ is the voltage deviation given by:

$V D=\sum_{i=1}^{N p q}\left|V_{i}-1\right|$

\section{Equality Constraint}

The equality constraint of the Reactive power problem is represented by the power balance equation, and can be written as, where the total power generation must cover the total power demand and total power loss:

$P_{G}=P_{D}+P_{L}$

Where, $P_{G}$ - Total Power Generation, $P_{D}$-Total Power Demand, $P_{L}-$ Total Power Loss.

\section{Inequality Constraints}

Inequality constraints define the limitations in power system components and power system security. Upper and lower bounds on the active power of slack bus, and reactive power of generators are written as follows:

$P_{\text {gslack }}^{\min } \leq P_{\text {gslack }} \leq P_{\text {gslack }}^{\max }$

$Q_{g i}^{\min } \leq Q_{g i} \leq Q_{g i}^{\max }, i \in N_{g}$

Upper and lower bounds on the bus voltage magnitudes are described as follows:

$V_{i}^{\min } \leq V_{i} \leq V_{i}^{\max }, i \in N$

Upper and lower bounds on the transformers tap ratios are given as follows:

$T_{i}^{\text {min }} \leq T_{i} \leq T_{i}^{\text {max }}, i \in N_{T}$

Upper and lower bounds on the compensators reactive powers are written as follows: 
$Q_{C}^{\min } \leq Q_{c} \leq Q_{C}^{\max }, i \in N_{C}$

Where $\mathrm{N}$ is the total number of buses, $\mathrm{N}_{\mathrm{T}}$ is the total number of Transformers; $\mathrm{N}_{\mathrm{c}}$ is the total number of shunt reactive compensators.

\section{Particle Swarm Optimization Algorithm}

Particle swarm optimization algorithm is an optimization algorithm based on group and fitness. The system initializes particles (representing potential solutions) as a set of random solutions, which has two features of position and velocity. The fitness values of particles are decided by particle positions. Particles move in the solution space; the moving direction and distance are determined by the speed vector and new speed, position are updated from personal best position pbest, global best position gbest and the current particle velocity; particles search and pursue the optimal particle based on fitness values in the solution space, and gradually converge to the optimal solution. Assuming in a d-dimensional search space, there is a group composed of $n$ particles, where of generation $\mathrm{t}$ particle $\mathrm{i}(\mathrm{i}=1,2, \ldots, \mathrm{n})$, position coordinates $x_{i}^{t}=\left(x_{i 1}, x_{i 2}, \ldots, x_{i d}\right)$, velocity $v_{i}^{t}=\left(v_{i 1}, v_{i 2}, \ldots v_{i d}\right)$ personal best position $p_{i}^{t}=\left(p_{i 1}, p_{i 2}, \ldots, p_{i d}\right)$ and global best position $p_{g}^{t}=\left(p_{g 1}, p_{g 2}, \ldots, p_{g d}\right)$. For particle i dimension $\mathrm{d}$ generation $\mathrm{t}$, its iterative formula can be expressed as:

$v_{i d}^{t+1}=\omega \vartheta_{i d}^{t}+c_{1} r_{1}\left(p_{i d}^{t}-x_{i d}^{t}\right)+c_{2} r_{2}\left(p_{g d}^{t}-x_{i d}^{t}\right)$

$x_{i d}^{t+1}=x_{i d}^{t}+\vartheta_{i d}^{t+1}$

Where, $\vartheta_{i d}^{t}$ - current velocity,

$\vartheta_{i d}^{t+1}$ - New speed of particle $\mathrm{r}$ after iteration $\mathrm{t}$,

$\omega$ - Inertia weight,

$c_{1}, c_{2}$ - Acceleration (learning) factors,

$r_{1}, r_{2}$ - Uniformly distributed random numbers between 0 and 1 ,

$x_{i d}^{t}$-current position of particle $\mathrm{i}$,

$x_{i d}^{t+1}$-new position of particle $\mathrm{i}$ after iteration $\mathrm{t}$.

\section{Frog Leaping Algorithm}

Frog leaping algorithm is a biological evolution algorithm based on swarm intelligence. The algorithm simulates a group of frogs in the wetland passing thought and foraging by classification of ethnic groups. In the execution of the algorithm, F frogs are generated at first to form a group, for $\mathrm{N}$-dimensional optimization problem, frog $\mathrm{i}$ of the group is represented as $X_{i}=\left(x_{i}^{1}, x_{i}^{2}, \ldots, x_{i}^{N}\right)$ then individual frogs in the group are sorted in descending order according to fitness values, to find the global best solution $\mathrm{P}_{\mathrm{x}}$. The group is divided into $\mathrm{m}$ ethnic groups, each ethnic group including $\mathrm{n}$ frogs, satisfying the relation $\mathrm{F}=\mathrm{m} \times \mathrm{n}$. The rule of ethnic group division is: the first frog into the first sub-group, the second frog into the second sub-group, frog $m$ into sub-group $m$, frog $m+1$ into the first sub-group again, frog $m+2$ into the second subgroup, and so on, until all the frogs are divided, then find the best frog in each sub-group, denoted by $\mathrm{P}_{\mathrm{b}}$; get a worst frog correspondingly, denoted by $\mathrm{P}_{\mathrm{w}}$. Its iterative formula can be expressed as: 
$D=\operatorname{rand}() *\left(P_{b}-P_{\omega}\right)$

$P_{\text {new }-\omega}=P_{\omega}+D_{i},-D_{\max } \leq D_{i} \leq D_{\max }$

Where rand ( ) represents a random number between 0 and 1 ,

$\mathrm{P}_{\mathrm{b}}$ represents the position of the best frog,

$\mathrm{P}_{\mathrm{w}}$ represents the position of the worst frog,

D represents the distance moved by the worst frog,

$P_{\text {new }}-\omega$ is the improved position of the frog,

$\mathrm{D}_{\max }$ represents the step length of frog leaping.

In the execution of the algorithm, if the updated $P_{n e w_{-}-\omega}$ is in the feasible solution space, calculate the corresponding fitness value of $P_{n e w_{-}-\omega}$, if the corresponding fitness value of $P_{n e w_{-}-\omega}$ is worse than the corresponding fitness value of $\mathrm{P}_{\mathrm{w}}$, then use $\mathrm{P}_{\mathrm{w}}$ to replace $\mathrm{P}_{\mathrm{b}}$ in equation (12) and re-update $P_{n e w_{-}-\omega}$; if there is still no improvement, then randomly generate a new frog to replace $\mathrm{P}_{\mathrm{w}}$; repeat the update process until satisfying stop conditions.

\section{Improved Frog Leaping (IFL) Algorithm}

Exploration and exploitation has been a contradiction in the search process of swarm intelligence algorithms. Exploration stresses searching for a new search region in the global range, and exploitation is focused on fine search in local search area. Although particle swarm optimization algorithm is simple and its optimization performance is good, in the entire iterative process, exploration capability is strong and exploitation capability is weak in early period, at this time if particles fall on the neighbourhood of the best particle, they may flee the neighbourhood of the best particle, due to too strong exploration capability; exploration capability is weak and exploitation capability is strong in later period, at this time if particles encounter local optima, the speed of all particles may be rapidly reduced to zero instead of flying, leading to convergence of particle swarm to local optima; the iterative mechanism and ethnic group division lead to strong exploitation and weak exploration in early period, and strong exploration and weak exploitation in later period. Based on the above analysis, in the update process of the algorithm, in order to ensure the diversity of particles, particle swarm and frog group sharing part of the particles, we propose particle sharing based particle swarm frog leaping hybrid optimization algorithm. The idea is as follows: divide the total number of particles $\mathrm{N}$ into two sub-groups of numbers N1 and N2, where the first sub-group uses shuffled frog leaping algorithm to optimize, the second sub-group uses the standard particle swarm optimization algorithm to optimize, and $\mathrm{N}, \mathrm{N} 1$ and $\mathrm{N} 2$ satisfy $\mathrm{N} \leq \mathrm{N} 1+\mathrm{N} 2$, so the number of shared particles is $\mathrm{N} 1+\mathrm{N} 2-\mathrm{N}$.

1) Initialize groups and parameters. Initialize group total number of particles $\mathrm{N}$, total number of frogs $\mathrm{N} 1$, number of sub-groups $\mathrm{m}$, number of frogs in each sub-group $\mathrm{n}$ (parameters satisfying $\mathrm{N}_{1}=\mathrm{m} \times \mathrm{n}$ ), number of updates It within frog group sub-group, number of particles $\mathrm{N}_{2}$ of particle swarm (parameters satisfying $\mathrm{N} \leq \mathrm{N} 1+\mathrm{N} 2$ ), inertia weight $\omega$, acceleration factor $c_{1}$, deceleration factor $c_{2}$, the maximum number of iterations Iter Max and other parameters.

2) Evaluate the initial fitness values of the particles, save the initial best positions and the initial best fitness values, and sort all $\mathrm{N}$ particles in ascending order according to fitness 
values; $\mathrm{N}_{1}$ particles counted from front to back belong to the frog group, and $\mathrm{N}_{2}$ particles counted from back to front belong to the particle swarm.

3) Sort $\mathrm{N}_{1}$ frogs in ascending order and divide them into sub-groups according to the subgroup division rule.

4) Determine the best fitness individual $P_{b}$ and the worst fitness individual $P_{w}$ of each subgroup in frog group, and the group best individual $\mathrm{P}_{\mathrm{x}}$, improve the worst solution within a specified number of iterations It according to equations (12) and (13).

5) Sort particles of the group in ascending order according to fitness values, re-mix the particles to form a new group, and sort the $\mathrm{N}$ particles in ascending order according to fitness values; $\mathrm{N}_{1}$ particles counted from front to back belong to the frog group, and N2 particles counted from back to front belong to the particle swarm. Calculate the new speed of each particle according to equation (10), calculate the new position of each particle according to equation (11), limiting the maximum values of the new speed and position of each particle; update each particle's personal best fitness value and personal best position; update the global best fitness value and the global best position.

6) Sort particles of the group in ascending order according to fitness values, and re-mix the particles to form a new group.

7) If stop conditions are satisfied (the number of iterations exceeds the maximum allowable number of iterations or the optimal solution is obtained), the search stops, and output the position and fitness value of the first particle of the group; otherwise, return to step (c) to continue the search.

\section{Simulation Results}

At first Improved Frog Leaping (IFL) algorithm has been tested in standard IEEE-57 bus power system. The reactive power compensation buses are 18, 25 and 53. Bus 2, 3, 6, 8, 9 and 12 are PV buses and bus 1 is selected as slack-bus. The system variable limits are given in Table 1.

The preliminary conditions for the IEEE-57 bus power system are given as follows:

$\mathrm{P}_{\text {load }}=12.129$ p.u. Q $_{\text {load }}=3.060$ p.u.

The total initial generations and power losses are obtained as follows:

$\sum P_{G}=12.470$ p.u. $\sum Q_{G}=3.3161$ p.u.

$P_{\text {loss }}=0.25870$ p.u. $Q_{\text {loss }}=-1.2071$ p.u.

Table 2 shows the various system control variables i.e. generator bus voltages, shunt capacitances and transformer tap settings obtained after optimization which are within the acceptable limits. In Table 3, shows the comparison of optimum results obtained from proposed methods with other optimization techniques. These results indicate the robustness of proposed approaches for providing better optimal solution in case of IEEE-57 bus system.

Table 1: Variable Limits

\begin{tabular}{|l|l|l|l|l|l|l|l|}
\hline Reactive Power Generation Limits \\
\hline Bus no & 1 & 2 & 3 & 6 & 8 & 9 & 12 \\
\hline Qgmin & -1.4 & -.015 & -.02 & -0.04 & -1.3 & -0.03 & -0.4 \\
\hline Qgmax & 1 & 0.3 & 0.4 & 0.21 & 1 & 0.04 & 1.50 \\
\hline Voltage And Tap Setting Limits \\
\hline \\
\hline \\
vgmin
\end{tabular}




\begin{tabular}{|l|l|l|l|l|l|}
\hline 0.9 & 1.0 & 0.91 & 1.05 & 0.9 & 1.0 \\
\hline \multicolumn{3}{|l|}{ Shunt Capacitor Limits } \\
\cline { 1 - 3 } Bus no & 18 & 25 & 53 & \\
\cline { 1 - 3 } Qcmin & 0 & 0 & 0 & \\
\cline { 1 - 3 } & 10 & 5.2 & 6.1 & & \\
\hline
\end{tabular}

Table 2: Control variables obtained after optimization

\begin{tabular}{|l|l|}
\hline Control Variables & IFL \\
\hline V1 & 1.1 \\
\hline V2 & 1.030 \\
\hline V3 & 1.032 \\
\hline V6 & 1.020 \\
\hline V8 & 1.021 \\
\hline V9 & 1.006 \\
\hline V12 & 1.011 \\
\hline Qc18 & 0.0660 \\
\hline Qc25 & 0.200 \\
\hline Qc53 & 0.0471 \\
\hline T4-18 & 1.006 \\
\hline T21-20 & 1.041 \\
\hline T24-25 & 0.860 \\
\hline T24-26 & 0.871 \\
\hline T7-29 & 1.051 \\
\hline T34-32 & 0.872 \\
\hline T11-41 & 1.012 \\
\hline T15-45 & 1.030 \\
\hline T14-46 & 0.910 \\
\hline T10-51 & 1.020 \\
\hline T13-49 & 1.060 \\
\hline T11-43 & 0.910 \\
\hline T40-56 & 0.900 \\
\hline T39-57 & 0.950 \\
\hline T9-55 & 0.950 \\
\hline & \\
\hline
\end{tabular}

Table 3: Comparison results

\begin{tabular}{|l|l|l|l|l|}
\hline S.No. & Optimization Algorithm & Finest Solution & Poorest Solution & Normal Solution \\
\hline 1 & NLP [14] & 0.25902 & 0.30854 & 0.27858 \\
\hline 2 & CGA [14] & 0.25244 & 0.27507 & 0.26293 \\
\hline 3 & AGA [14] & 0.24564 & 0.26671 & 0.25127 \\
\hline 4 & PSO-w [14] & 0.24270 & 0.26152 & 0.24725 \\
\hline 5 & PSO-cf [14] & 0.24280 & 0.26032 & 0.24698 \\
\hline 6 & CLPSO [14] & 0.24515 & 0.24780 & 0.24673 \\
\hline 7 & SPSO-07 [14] & 0.24430 & 0.25457 & 0.24752 \\
\hline 8 & L-DE [14] & 0.27812 & 0.41909 & 0.33177 \\
\hline 9 & L-SACP-DE [14] & 0.27915 & 0.36978 & 0.31032 \\
\hline
\end{tabular}


DOI: 10.5281/zenodo.999199

\begin{tabular}{|l|l|l|l|l|}
\hline 10 & L-SaDE [14] & 0.24267 & 0.24391 & 0.24311 \\
\hline 11 & SOA [14] & 0.24265 & 0.24280 & 0.24270 \\
\hline 12 & LM [15] & 0.2484 & 0.2922 & 0.2641 \\
\hline 13 & MBEP1 [15] & 0.2474 & 0.2848 & 0.2643 \\
\hline 14 & MBEP2 [15] & 0.2482 & 0.283 & 0.2592 \\
\hline 15 & BES100 [15] & 0.2438 & 0.263 & 0.2541 \\
\hline 16 & BES200 [15] & 0.3417 & 0.2486 & 0.2443 \\
\hline 17 & Proposed IFL & 0.22064 & 0.23016 & 0.22248 \\
\hline
\end{tabular}

Then Improved Frog Leaping (IFL) algorithm has been tested in standard IEEE 118-bus test system [16]. The system has 54 generator buses, 64 load buses, 186 branches and 9 of them are with the tap setting transformers. The limits of voltage on generator buses are $0.95-1.1$ per-unit., and on load buses are 0.95 -1.05 per-unit. The limit of transformer rate is $0.9-1.1$, with the changes step of 0.025 . The limitations of reactive power source are listed in Table 4 , with the change in step of 0.01 .

Table 4: Limitation of reactive power sources

\begin{tabular}{|l|l|l|l|l|l|l|l|}
\hline BUS & 5 & 34 & 37 & 44 & 45 & 46 & 48 \\
\hline QCMAX & 0 & 14 & 0 & 10 & 10 & 10 & 15 \\
\hline QCMIN & -40 & 0 & -25 & 0 & 0 & 0 & 0 \\
\hline BUS & 74 & 79 & 82 & 83 & 105 & 107 & 110 \\
\hline QCMAX & 12 & 20 & 20 & 10 & 20 & 6 & 6 \\
\hline QCMIN & 0 & 0 & 0 & 0 & 0 & 0 & 0 \\
\hline
\end{tabular}

The statistical comparison results of 50 trial runs have been list in Table 5 and the results clearly show the better performance of proposed Improved Frog Leaping (IFL) algorithm in reducing the real power loss.

Table 5: Comparison results

\begin{tabular}{|l|l|l|l|l|}
\hline Active power loss (MW) & $\begin{array}{l}\text { BBO } \\
{[\mathbf{1 7}]}\end{array}$ & $\begin{array}{l}\text { ILSBBO/ } \\
\text { strategy1 } \\
{[\mathbf{1 7}]}\end{array}$ & $\begin{array}{l}\text { ILSBBO/ } \\
\text { strategy1 } \\
{[\mathbf{1 7}]}\end{array}$ & $\begin{array}{l}\text { Proposed } \\
\text { IFL }\end{array}$ \\
\hline Min & 128.77 & 126.98 & 124.78 & 117.86 \\
\hline Max & 132.64 & 137.34 & 132.39 & 119.54 \\
\hline Average & 130.21 & 130.37 & 129.22 & 118.42 \\
\hline
\end{tabular}

\section{Conclusion}

In this paper a novel approach Improved Frog Leaping (IFL) algorithm used to solve reactive power problem, considering various generator constraints, has been successfully applied.The performance of the proposed Improved Frog Leaping (IFL) algorithm has been has been tested in standard IEEE 57,118 bus systems and simuation results reveal about the reduction of real power loss when compared with other standard reported algorithms and volatge profiles are within the limits. 


\section{References}

[1] O.Alsac,and B. Scott, "Optimal load flow with steady state security",IEEE Transaction. PAS 1973, pp. 745-751.

[2] Lee K Y ,Paru Y M , Oritz J L -A united approach to optimal real and reactive power dispatch , IEEE Transactions on power Apparatus and systems 1985: PAS-104 : 1147-1153

[3] A.Monticelli , M .V.F Pereira, and S. Granville , "Security constrained optimal power flow with post contingency corrective rescheduling" , IEEE Transactions on Power Systems :PWRS-2, No. 1, pp.175-182.,1987.

[4] Deeb N ,Shahidehpur S.M ,Linear reactive power optimization in a large power network using the decomposition approach. IEEE Transactions on power system 1990: 5(2) : 428-435

[5] E. Hobson ,'Network consrained reactive power control using linear programming, ' IEEE Transactions on power systems PAS -99 (4), pp 868=877, 1980

[6] K.Y Lee ,Y.M Park, and J.L Oritz, "Fuel -cost optimization for both real and reactive power dispatches", IEE Proc; 131C,(3), pp.85-93.

[7] M.K. Mangoli, and K.Y. Lee, "Optimal real and reactive power control using linear programming", Electr.Power Syst.Res, Vol.26, pp.1-10,1993.

[8] K.Anburaja, "Optimal power flow using refined genetic algorithm", Electr.Power Compon.Syst , Vol. 30, 1055-1063,2002.

[9] D. Devaraj, and B. Yeganarayana, "Genetic algorithm based optimal power flow for security enhancement", IEE proc-Generation.Transmission and. Distribution; 152, 6 November 2005.

[10] C.A. Canizares , A.C.Z.de Souza and V.H. Quintana, " Comparison of performance indices for detection of proximity to voltage collapse," vol. 11. no.3, pp.1441-1450, Aug 1996.

[11] Kennedy J, Eberhart R C. "Particle swarm optimization", In Proceedings of IEEE International Conference on Neural Network, pages 1942 - 1948, 1995.

[12] Shi Y, Eberhart R C. "A modified particle swarm optimizer", In Proceedings of the IEEE International Conference on Evolutionary Computation, pages 69-73, 1998.

[13] Eusuff, Lansey. "Optimization of Water Distribution Network Design Using Shuffled Frog Leaping Algorithm”, Journal of Water Resources Planning and Management, 129 (3): 210 225, 2003.

[14] Chaohua Dai, Weirong Chen, Yunfang Zhu, and Xuexia Zhang, "Seeker optimization algorithm for optimal reactive power dispatch," IEEE Trans. Power Systems, Vol. 24, No. 3, August 2009, pp. 1218-1231.

[15] J. R. Gomes and 0. R. Saavedra, "Optimal reactive power dispatch using evolutionary computation: Extended algorithms," IEE Proc.-Gener. Transm. Distrib.. Vol. 146, No. 6. Nov. 1999.

[16] IEEE, "The IEEE 30-bus test system and the IEEE 118-test system", (1993), http://www.ee.washington.edu/trsearch/pstca/.

[17] Jiangtao Cao, Fuli Wang and Ping Li, "An Improved Biogeography-based Optimization Algorithm for Optimal Reactive Power Flow" International Journal of Control and Automation Vol.7, No.3 (2014), pp.161-176.

*Corresponding author.

E-mail address: gklenin@ gmail.com 